\title{
Study on Preparation of Eco-friendly Autoclaved Aerated Concrete from Low Silicon and High Iron Ore Tailings
}

\author{
Xiaoying Liang ${ }^{1,2}$, Changlong Wang ${ }^{2,3,4}$, Jiayu Zhan ${ }^{1 *}$, Xiaowei Cui $^{5}$ and Zhenzhen Ren $^{1}$ \\ ${ }^{1}$ State Key Laboratory of Solid Waste Reuse for Building Materials, Beijing Building Materials Academy of Science Research, Bei- \\ jing 100041,China; \\ ${ }^{2}$ School of Civil Engineering, Hebei University of Engineering, Handan Hebei Province, 056038, China; \\ ${ }^{3}$ Jiangxi Key Laboratory of Mining Engineering, Jiangxi University of Science and Technology, Ganzhou Jiangxi Province 341000, \\ China; \\ ${ }^{4}$ Tianjin Sunenergy Sega Environmental Science \& Technology Co. Ltd, Tianjin 300000, China; \\ ${ }^{5}$ Shaanxi Key Laboratory of Comprehensive Utilization of Tailings Resources, Shangluo University, Shangluo Shaanxi Province \\ 726000, China
}

Corresponding Author Email: baistuwong@139.com; zhanjiayu1981@126.com

\begin{abstract}
In order to realize the resource utilization of solid waste, autoclaved aerated concrete (ACC) was prepared with low silicon and high iron tailings (IOT) as the main siliceous materials. The effects of fineness and content of siliceous materials, and static curing temperature on the AAC properties, hydration products and microstructures of AAC were investigated by physical and mechanical properties test, X-ray diffraction analysis (XRD), and scanning electron microscope (SEM). The result shows that the AAC containing 40\% IOT (in mass percentage) with a specific surface area (SSA) of $311 \mathrm{~m}^{2} \cdot \mathrm{kg}-1$ can achieve a compressive strength of $4.15 \mathrm{MPa}$ and bulk density of $587 \mathrm{~kg} \cdot \mathrm{m}^{-3}$, which qualifies the requirements of B06, A3.5 of AAC sample regulated by the composition and morphology GB/T 11969-2008. And the main phases in the system contain hydration products, ferrotschermakite, hornblende, anhydrite, calcite, dolomite and residual quartz. The main hydration products are $0.9 \mathrm{~nm}, 1.1 \mathrm{~nm}$ and 1.4 $\mathrm{nm}$ tobermorite and C-S-H gels. And the strength mainly results from cementation between hydration products tobermorite and C-S-H gels and unreacted components.
\end{abstract}

Keywords: iron ore tailings, autoclaved aerated concrete, fineness, content, tobermorite

Received: August-04-2019, Accepted: October-15-2019, https://doi.org/10.14447/jnmes.v22i4.a08

\section{INTRODUCTION}

Iron ore tailings (IOT) are the industrial solid waste from iron separation. With the rapid development of the steel industry, the proportion of the IOT in the industrial solid waste industry has been also increasing. There are more than 400 large-scale tailings dams in China, among which the tailings impoundment from metal mines reaches over 6 billion tons. At present, tailings are still growing at a rate of 300 million tons per year, with the IOT accounting for $1 / 3$ of them [1-3]. Therefore, whether it is used as a secondary resource or a source of pollution, the IOT have been one of the key research topics of mining enterprises, universities and research institutes. The comprehensive utilization of tailings in China mainly focuses on the extraction of valuable elements $[4,5]$, the production of construction materials [6$11]$, and the use as filling materials $[12,13]$. In recent years, the IOT have been used as new siliceous materials to prepare the autoclaved aerated concrete (AAC). Li et al. [14] used Miyun IOT to prepare the AAC products with a content of $62 \%$ and a compressive strength of 6 $\mathrm{MPa}$; however, the siliceous materials used were high-silicon low-iron tailings, and the process cannot meet the requirements for preparing the AAC product with low-silicon, high-iron, and silicate-rich tailings, resulting in a low rate of achievement transformation and promotion rate. Based on the related research results, this paper attempts to study the preparation of the AAC using the low-silicon and high-iron tail- ings. For this, taking the low-silicon high-iron-type silicate-rich tailings as the main raw material, it explores the basic process of preparing the AAC through the iron ore tailings-silica sand-cement-lime raw material system, and analyses the effect of the fineness of raw materials, mixing amount, and static curing time on the AAC performance. Also, testing methods of X-ray diffraction analysis (XRD), and scanning electron microscope (SEM) were used to study the hydration products types and micro-morphology of the AAC.

\section{MATERIALS AND METHODS}

\subsection{Materials}

(1) IOT. The IOT from Shanxi Lingqiu Haoyang Mining Co., Ltd was precipitated, dried, mixed, and reduced during the mine separation process of the comprehensive tailings in the ore dressing plant, to obtain the representative research samples in this study. The results of phase analysis (Fig. 1) show that the main phases of the IOT are composed of quartz, hornblende, grunerite, and plagioclase, as well as rare biotite, chlorite, and calcite; the main chemical composition of the IOT include $\mathrm{SiO}_{2}, \mathrm{Al}_{2} \mathrm{O}_{3}, \mathrm{Fe}_{2} \mathrm{O}_{3}$, and $\mathrm{FeO}$; the $\mathrm{Fe}$ content in the tailings is relatively high, and the total iron content $\mathrm{TFe}$ is $14.51 \%$ (Table 1 ); also, the IOT studied are high-iron, low-silicon, and iron silicate-rich. Because the $\mathrm{SiO}_{2}$ content in the iron tailings of $54.41 \%$ do not meet the requirement in the AAC production, it's necessary to add silica 
Table 1. Chemical composition of raw materials (mass fraction, \%)

\begin{tabular}{lccccccccccccccc}
\hline Materials & $\mathrm{SiO}_{2}$ & $\mathrm{Al}_{2} \mathrm{O}_{3}$ & $\mathrm{Fe}_{2} \mathrm{O}_{3}$ & $\mathrm{FeO}$ & $\mathrm{MgO}$ & $\mathrm{CaO}$ & $\mathrm{Na}_{2} \mathrm{O}$ & $\mathrm{K}_{2} \mathrm{O}$ & $\mathrm{SO}_{2}$ & $\mathrm{Loss}^{2}$ \\
\hline IOT & 54.41 & 7.99 & 8.94 & 10.65 & 5.75 & 5.06 & 0.98 & 0.43 & 1.26 & 2.90 \\
$\mathrm{SS}$ & 87.07 & 5.87 & 0.64 & 0.19 & 0.97 & 1.34 & 1.00 & 1.90 & - \\
Lime & 5.45 & 3.85 & 1.68 & 0.08 & 3.59 & 78.76 & - & 1.25 & 0.45 & 3.93 \\
OPC & 25.06 & 6.10 & 3.31 & 0.21 & 3.87 & 55.56 & 0.23 & 0.95 & - & 4.16 \\
FGDG & 2.84 & 0.78 & 0.25 & 0.03 & 0.47 & 40.13 & 0.14 & 0.12 & 33.21 & - \\
\hline
\end{tabular}

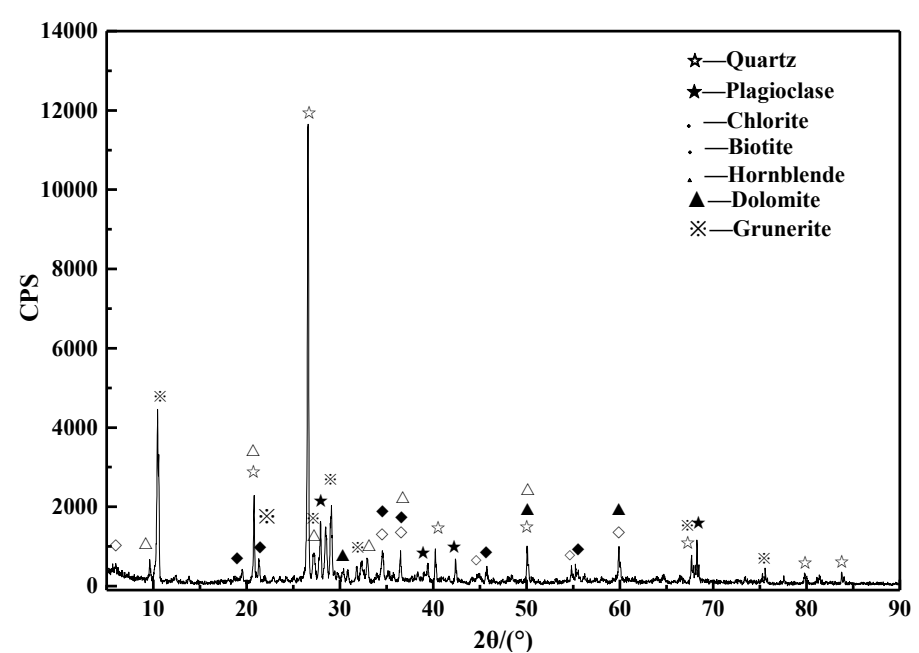

Figure 1. XRD spectra of IOT

sand with a higher $\mathrm{SiO}_{2}$ content as the siliceous materials.

(2) Silica sand (SS). Using the aeolian sand in industrial production. Its chemical composition is shown in Table 1. The XRD analysis results are shown in Fig. 2. It can be seen from Table 1 that the $\mathrm{SiO}_{2}$ content of SS reached $87.17 \%$, satisfying the requirements for use. Fig. 2 shows a high content of quartz in the SS used in the test.

(3) Lime. Using the commercial quick lime, with the fineness controlled about $0.08 \mathrm{~mm}$, and square hole sieve with less than $15 \%$ sieve. After testing, its effective $\mathrm{CaO}$ content is $74 \%, \mathrm{MgO}$ content is $3.59 \%$, $\mathrm{SiO}_{2}$ is $5.45 \%$, digestion time is $13 \mathrm{~min}$, and digestion temperature is 66 ${ }^{\circ} \mathrm{C}$, in line with the requirements of the national standard $\mathrm{JC} / \mathrm{T} 621$ 2009 Lime for Silicate Building Products. Its chemical composition is shown in Table 1.

(4) Ordinary Portland cement (OPC). The commercially available P.O 42.5 ordinary Portland cement. Its chemical composition is shown in Table 1. The initial setting time of the cement is 118 minutes and the final setting time is 390 minutes, in line with the quality requirements of cement in GB 175-2007 Common Portland Cement.

(5) Flue Gas Desulfurization gypsum (FGDG). It's from Beijing Jingneng Power Co., Ltd., with $8 \%$ residue on $0.08 \mathrm{~mm}$ square-hole sieve. Its chemical composition is shown in Table 1.

(6) Aluminium powder. FQ-80B type hydrophilic Al powder is used in the test. Its active $\mathrm{Al}$ content is $92 \%$, the $2.6 \%$ residue on the $0.08 \mathrm{~mm}$ square hole sieve, the aeration rate is greater than $80 \%$, the aeration time is less than 24 minutes, and the hydrophilicity is less than 20 seconds.

\section{2 Methods}

The IOT and SS were first dried to a moisture content of less than $1 \%$, and then placed in a $5 \mathrm{~kg}$ laboratory ball mill (SM $4500 \mathrm{~mm} \times 500$ $\mathrm{mm}$ ) for grinding. The rotation speed of the mill was $48 \mathrm{r} \cdot \mathrm{min}^{-1}$, the grinding medium was steel balls and steel forging, and the loading

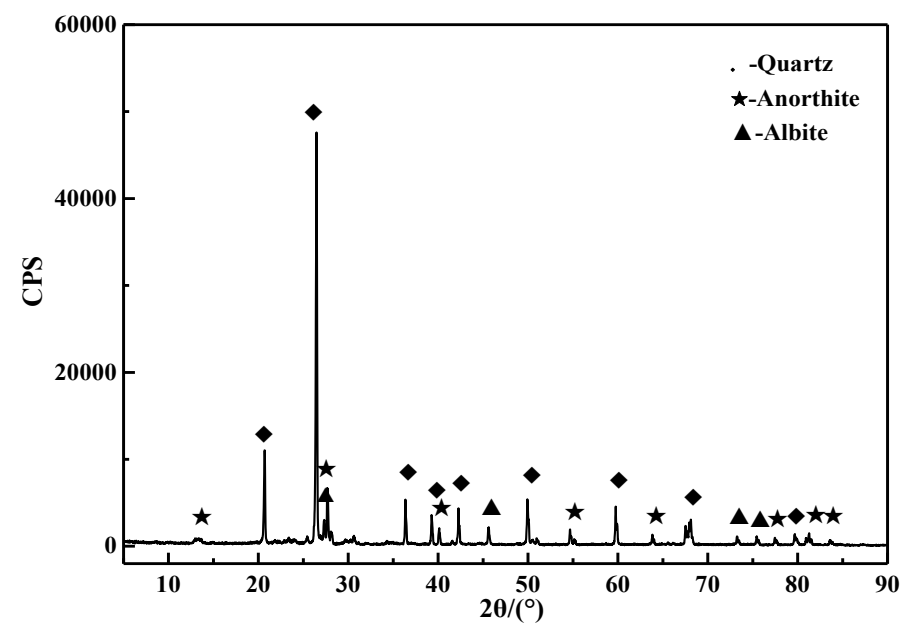

Figure 2. XRD spectra of the SS

capacity of the grinding medium was $100 \mathrm{~kg}$. Among them, the steel ball was $60 \mathrm{~kg}$; the quality gradation was $\varphi 70 \mathrm{~mm}$ accounting for

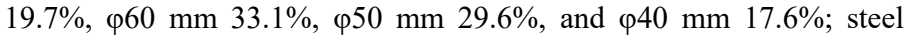
forging was $40 \mathrm{~kg}, \varphi 25 \mathrm{~mm} \times 30 \mathrm{~mm}$ in size. The purpose of this study is to prepare A3.5, B06-class AAC products adopted with the IOT. After the ratio optimization test, the basic formula of the raw materials was determined. Based on this, the AAC performance was tested according to the national standard using a $100 \mathrm{~mm} \times 100 \mathrm{~mm} \times 100 \mathrm{~mm}$ test mould. The process of sample preparation is as follows: according to the mixing ratio, mix the ground iron tailings and SS with lime, cement, and FGDG, and add warm water at $55^{\circ} \mathrm{C}$ for $90 \mathrm{~s}$; then add aluminium paste and stir for $40 \mathrm{~s}$. After pouring, static curing, demoulding, autoclaving process, the AAC samples were finished. The ambient temperature of aeration and static curing was $40 \sim 70{ }^{\circ} \mathrm{C}$. After 4 hours of static curing, the strength of the test sample can meet the requirements of the cutting process in production. In this test, the forming and pre-curing of the test pieces were completed in the laboratory, and then the green body was transported to the factory for saturated steam pressure autoclaving using an industrial autoclave. The autoclaving system was: temperature rise for 2 hours, constant temperature for 8 hours (maximum pressure $1.25 \mathrm{MPa}$, and temperature $185{ }^{\circ} \mathrm{C}$ ), temperature reduction for $2 \mathrm{~h}$ for obtaining the $\mathrm{AAC}$ products.

\subsection{Characterization of the AAC properties}

This study aims to produce the AAC products doped with the IOT with a volume mass of $600 \mathrm{~kg} \cdot \mathrm{m}^{-3}$ (B06 class). In the test, the physical and mechanical properties of such AAC products were measured in accordance with the national standard Test methods of autoclaved aerated concrete (GB/ T11969-2008)". When testing the compressive strength and bulk density, the moisture content of the product was controlled to $8 \% \sim 12 \%$.

CZB-9 automatic specific surface area meter (SSA) was used to 
Table 3. The influence of different fineness of IOT on pouring stability and AAC properties

\begin{tabular}{lccccc}
\hline Number & $\begin{array}{c}\text { SSA } \\
/\left(\mathrm{m}^{2} \cdot \mathrm{kg}^{-1}\right)\end{array}$ & $\begin{array}{c}\text { Slurry } \\
\text { fluidity }\end{array}$ & $\begin{array}{c}\text { Pouring } \\
\text { stability }\end{array}$ & $\begin{array}{c}\text { Bulk density } \\
/\left(\mathrm{kg} \cdot \mathrm{m}^{-3}\right)\end{array}$ & $\begin{array}{c}\text { Compressive } \\
\text { strength/MPa }\end{array}$ \\
\hline T1 & 225 & poor & bubble & 620 & 1.83 \\
T2 & 244 & poor & bubble & 612 & 1.98 \\
T3 & 286 & general & good & 603 & 2.05 \\
T4 & 311 & good & good & 595 & 2.41 \\
T5 & 345 & good & better & 596 & 2.35 \\
T6 & 385 & good & better & 608 & 2.18 \\
T7 & 429 & better & slight bubble & 623 & 2.14 \\
\hline
\end{tabular}

measure the SSA of the ground raw materials; YES-300 digital display and hydraulic pressure testing machine was adopted to test the mechanical properties, with the maximum load of $300 \mathrm{KN}$, and the loading rate of $(2.0 \pm 0.5) \mathrm{kN} / \mathrm{s}$; a Rigaku D/MAX-RC 12KW XRD was applied to analyse the AAC samples, $\mathrm{Cu}$ target, with a wavelength of $1.5406 \mathrm{~nm}$, a working current of $150 \mathrm{~mA}$, and a working voltage of $40 \mathrm{kV}$; Zeiss SUPERTM $^{55}$ field emission Scanning electron microscope (FE-SEM) was used to observe the morphology of hydration products in the AAC samples.

\section{RESULTS AND DISCUSSION}

\subsection{Effect of IOT fineness on the AAC properties}

The grinding time of the IOT and SS is a key factor in the preparation of the AAC. The size of IOT and SS particles directly affects the stability of slurry casting and the level of the AAC reaction activity. Studies have shown that when the product system cured by autoclaving is mixed with ground IOT and SS, the crystalline silica in the system has the conditions to participate in the hydration reaction. The ground IOT and SS not only has a filling effect, but also can cause substantial chemical reactions to generate the main phases of the AAC. The IOT and SS used in the test were relatively low in activity. To be used as a cementing material in the AAC, they must first be activated. The reaction activation energy of materials is decreased through mechanochemical effects [15-17]. The mechanical force reduces the particle size of the raw material particles, increases the SSA, and generates many new surfaces. With the surface free energy increasing, the reactivity also increases.

\subsubsection{Determination of IOT fineness}

The residue on $0.08 \mathrm{~mm}$ square hole sieve of the raw IOT is $70.80 \%$, which cannot be directly used to produce the AAC. They should be ground and homogenized by a ball mill. The grinding time and the corresponding SSA are shown in Fig. 3.

The AAC was prepared from IOT of different grinding fineness, and the casting stability and product properties were tested to determine the grinding fineness of the IOT. The main raw material ratio (mass percentage) in the test tentatively determined in this test was: IOT $60 \%$, OPC $12 \%$, lime $23 \%$, FGDG $5 \%$, water and aluminium powder consumption for $58 \%$ and $0.06 \%$ of the total dry materials, mixing temperature $55{ }^{\circ} \mathrm{C}$, and curing temperature $55^{\circ} \mathrm{C}$. Table 3 shows the influence of the IOT with different fineness on the AAC performance under the same test conditions.

Table 3 The influence of different fineness of IOT on pouring stability and AAC properties

Table 3 shows that the effect of the IOT fineness on its reactivity plays a vital role in the stability of the slurry. As with cementitious materials such as cement, improving the fineness can increase SSA of

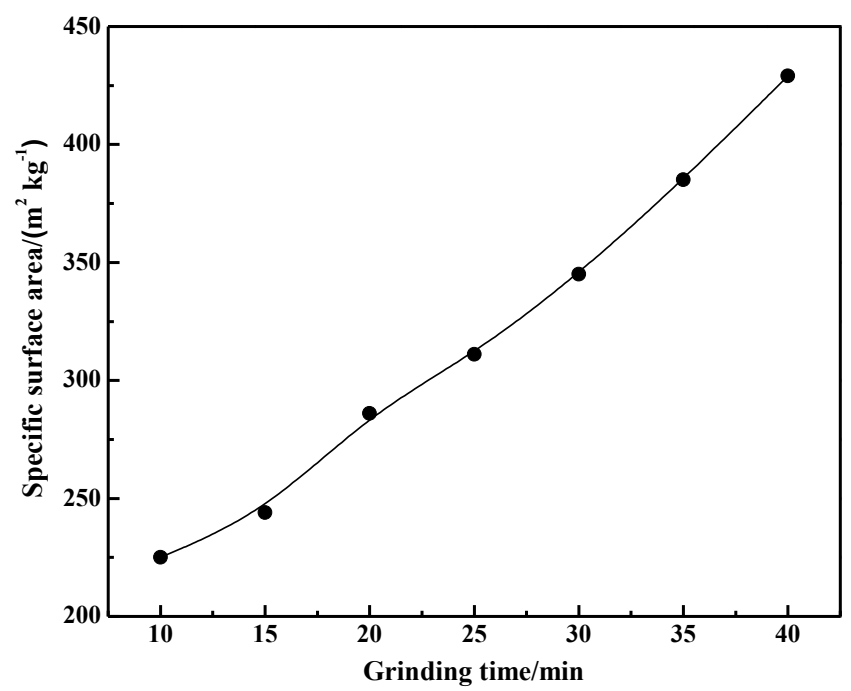

Figure 3. Relationship between grinding time and SSA of IOT

the IOT in contact with water. As a result, the new surface crystals are ground and broken, and become amorphous, which increases the dissolution rate, and enhances the ability of materials to participate in chemical reactions, thereby stimulating the activation of the IOT. The finer the IOT, then the larger the SSA of the particles participating in the reaction, the higher the activity, the better the fluidity of the slurry, but at the same time, it is easy to cause the slurry to be too thick, resulting in insufficient aeration. When the IOT powder is ground to below dozens of microns, it shall fail to provide a good framework structure for the product, resulting in a poor pore structure, which is consistent with the conclusions obtained by observing the appearance effect of the AAC samples. The IOT have coarse particles, poor slurry fluidity, fast settlement after pouring, and are liable to cause mould collapse and subsidence. The results of this test prove that as the grinding time of the IOT increases, the compressive strength of the sample increased first and then decreased; when the grinding for 25 minutes, the enhancement effect reaches the maximum value, and the AAC sample looks the best. Therefore, considering the economic and performances, the SSA of the tailings during the subsequent tests was determined to be $311 \mathrm{~m}^{2} \cdot \mathrm{kg}^{-1}$ (grinding time $25 \mathrm{~min}$ ).

If the low-silicon and high-iron tailings used in this test were not doped with siliceous materials, it would have been difficult to produce samples meeting the requirements of A3.5 and B06-class qualified products. Thus, high-silica materials such as SS at reasonable ratio should be added to improve the $\mathrm{SiO}_{2}$ required for the reaction, provide the aggregate of the skeleton required by the product, and find out the optimal point between the IOT and the SS, thereby improving the overall strength of the AAC samples.

\subsubsection{Determination of silica sand fineness}

The residue on $0.08 \mathrm{~mm}$ square hole sieve of the original $\mathrm{SS}$ is $30.21 \%$. The grinding time of SS and the corresponding SSA are shown in Fig. 4.

The AAC was prepared from SS with different SSA. The amount of SS used in the test was $60 \%$, while the amount of the other raw materials and curing conditions were the same as those of the AAC with different fineness. Table 4 shows the influence of SS with different fineness on the performance of the AAC under the same test conditions.

Table 4 shows that the bulk density and compressive strength of the samples increased significantly with the extension of the SS grinding time. The compressive strength of the AAC sample was the maximum under the premise of the fine grinding for 35 minutes. When grinding 
Table 4. The influence of different grinding time of SS on pouring stability and AAC properties

\begin{tabular}{lccccc}
\hline Number & $\begin{array}{c}\text { SSA } \\
/\left(\mathrm{m}^{2} \cdot \mathrm{kg}^{-1}\right)\end{array}$ & $\begin{array}{c}\text { Slurry } \\
\text { fluidity }\end{array}$ & $\begin{array}{c}\text { Pouring } \\
\text { stability }\end{array}$ & $\begin{array}{c}\text { Bulk density } \\
/\left(\mathrm{kg} \cdot \mathrm{m}^{-3}\right)\end{array}$ & $\begin{array}{c}\text { Compressive } \\
\text { strength/MPa }\end{array}$ \\
\hline S1 & 187 & poor & bubble & 575 & 3.04 \\
S2 & 199 & poor & bubble & 582 & 3.14 \\
S3 & 221 & general & better & 588 & 3.41 \\
S4 & 276 & good & better & 588 & 3.60 \\
S5 & 334 & good & good & 591 & 4.46 \\
S6 & 348 & good & good & 594 & 4.51 \\
S7 & 387 & better & slight bubble & 598 & 4.37 \\
\hline
\end{tabular}

time was continued, the compressive strength of the sample was reduced. From the surface of the sample, when the SS grinding time is short, it shall result in coarse SS particles, small contact surface with the slurry quicklime, insufficient reaction, poor workability of the slurry, and the liability to produce honeycomb phenomenon. On the contrary, the long grinding time of SS can lead to a small amount of aggregate, the lack of the proper skeleton in the product, and increase the shrinkage value of the AAC sample, which easily causes the cracks to appear around the AAC sample, and is not conducive to use. When grinding the SS for 35 minutes, the slurry fluidity and pouring stability are good, but large cracks may appear on the outer surface of the product perpendicular to the aeration direction. Therefore, considering the pouring stability, product performance, grinding energy consumption, economy and other factors, it's determined that the grinding time of SS was 30 minutes (SSA: $334 \mathrm{~m}^{2} \cdot \mathrm{kg}^{-1}$ ).

\subsection{Effect of IOT content on the AAC properties}

IOT with a fineness of $311 \mathrm{~m}^{2} \cdot \mathrm{kg}^{-1}$ and SS with a fineness of 334 $\mathrm{m}^{2} \cdot \mathrm{kg}^{-1}$ were used for the admixture test. In the test the amount of FGDG used as a regulator was tentatively set at $5 \%$, while the other test conditions were the same as that of the fineness testing: the mixing amount of the IOT was selected to be $30 \%, 35 \%, 40 \%, 45 \%, 50 \%$, and $55 \%$ respectively in order to maximize the use of the IOT; the content

Table 5. The effect of different content of IOT on AAC properties

\begin{tabular}{|c|c|c|c|c|c|c|c|}
\hline \multirow{2}{*}{ Number } & \multicolumn{5}{|c|}{ Ratio of raw materials (\%) } & \multirow{2}{*}{$\begin{array}{l}\text { Bulk density } \\
/\left(\mathrm{kg} \cdot \mathrm{m}^{-3}\right)\end{array}$} & \multirow{2}{*}{$\begin{array}{l}\text { Compressive } \\
\text { strength/MPa }\end{array}$} \\
\hline & IOT & SS & Lime & OPC & FGDG & & \\
\hline A1 & 30 & 30 & 20 & 15 & 5 & 604 & 4.16 \\
\hline A2 & 30 & 30 & 25 & 10 & 5 & 596 & 4.10 \\
\hline A3 & 30 & 30 & 30 & 5 & 5 & 590 & 4.05 \\
\hline A4 & 35 & 25 & 20 & 15 & 5 & 593 & 4.18 \\
\hline A5 & 35 & 25 & 25 & 10 & 5 & 591 & 4.17 \\
\hline A6 & 35 & 25 & 30 & 5 & 5 & 587 & 4.09 \\
\hline A7 & 40 & 20 & 20 & 15 & 5 & 592 & 4.17 \\
\hline A 8 & 40 & 20 & 25 & 10 & 5 & 587 & 4.15 \\
\hline A9 & 40 & 20 & 30 & 5 & 5 & 582 & 4.10 \\
\hline A 10 & 45 & 15 & 20 & 15 & 5 & 598 & 4.14 \\
\hline A11 & 45 & 15 & 25 & 10 & 5 & 590 & 4.11 \\
\hline A 12 & 45 & 15 & 30 & 5 & 5 & 588 & 4.06 \\
\hline A 13 & 50 & 10 & 20 & 15 & 5 & 599 & 3.84 \\
\hline A14 & 50 & 10 & 25 & 10 & 5 & 593 & 3.79 \\
\hline A15 & 50 & 10 & 30 & 5 & 5 & 588 & 3.64 \\
\hline A16 & 55 & 5 & 20 & 15 & 5 & 602 & 3.45 \\
\hline A17 & 55 & 5 & 25 & 10 & 5 & 598 & 3.39 \\
\hline A18 & 55 & 5 & 30 & 5 & 5 & 595 & 3.25 \\
\hline
\end{tabular}

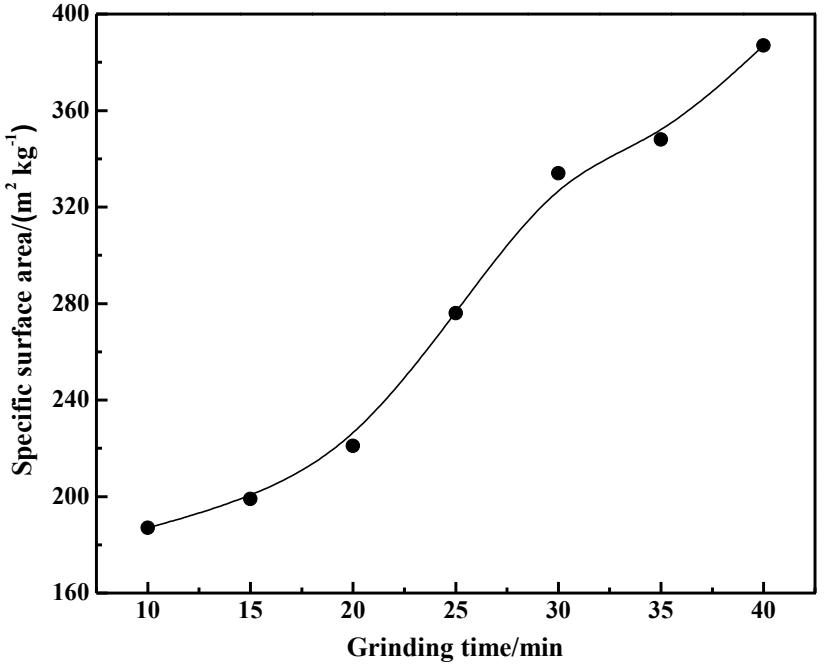

Figure 4. Relationship between grinding time and SSA of SS

of SS was $5 \%, 10 \%, 15 \%, 20 \%$, and $25 \%$, and $30 \%$ respectively, lime content was $20 \%, 25 \%, 30 \%$, and OPC content was $5 \%, 10 \% 15 \%$, aluminium paste $1.32 \mathrm{~g}$, water $1276 \mathrm{~g}$, mixing temperature $55^{\circ} \mathrm{C}$ of warm water, static curing temperature of $55^{\circ} \mathrm{C}$. Thus, according to the low-to-high calcium-silicon ratio, and low-to-high cement-lime ratio, the test plan was designed to study the influence of the IOT content on the AAC properties. Table 5 shows the mix ratio and physical and mechanical properties of the main raw materials.

The data in Table 5 shows that with the OPC content of $10 \%$ and $15 \%$, and the lime content of $20 \%$ and $25 \%$, the compressive strength of the product was higher. With the purpose to maximize the use of the IOT and reduce costs of the product, the mixing ratio of A8 products was selected to be the optimal one, i.e., the amounts of the IOT, SS, lime, OPC, and FGDG are $40 \%, 20 \%, 25 \%, 10 \%$, and $5 \%$.

Under the condition of the same raw material mixture ratio, the different static curing temperature shall cause the speed of slurry thickening after casting to vary. Also, the speed of slurry thickening is not completely coordinated with the aeration speed of aluminium paste. In order to acquire the best product performance, it is necessary to keep the speed of the two synchronized, which is conducive to the formation of a better pore structure in the moulding of the product, and to ensure that the product obtains better strength after autoclaving. This test used A8 ratio to test the effect of curing temperature on the AAC performance. The test results are shown in Table 6.

It can be seen from Table 6 that when the static curing temperature was $40 \sim 60{ }^{\circ} \mathrm{C}$, the compressive strength and specific strength of the AAC samples increased; when it was $60 \sim 70{ }^{\circ} \mathrm{C}$, the compressive strength decreased; at a curing temperature of $60^{\circ} \mathrm{C}$, the AAC product had the highest compressive strength, reaching 4.20 $\mathrm{MPa}$. This indicates that the increase of the static curing temperature is beneficial to the strength development of the product, but the high temperature can cause the water to vaporizes too quickly during the moulding process of the product, resulting in inconsistency between the slurry thickening speed and the aluminium 
Table 6. The influence of static curing temperature on AAC properties

\begin{tabular}{lccc}
\hline Number & $\begin{array}{c}\text { Curing Temperature } \\
/{ }^{\circ} \mathrm{C}\end{array}$ & $\begin{array}{c}\text { Bulk density } \\
/\left(\mathrm{kg} \cdot \mathrm{m}^{-3}\right)\end{array}$ & $\begin{array}{c}\text { Compressive } \\
\text { strength/MPa }\end{array}$ \\
\hline $\mathrm{C} 1$ & 40 & 593 & 3.85 \\
$\mathrm{C} 2$ & 45 & 590 & 4.02 \\
$\mathrm{C} 3$ & 50 & 591 & 4.12 \\
$\mathrm{C} 4$ & 55 & 587 & 4.15 \\
$\mathrm{C} 5$ & 60 & 588 & 4.20 \\
$\mathrm{C} 6$ & 65 & 590 & 4.17 \\
$\mathrm{C} 7$ & 70 & 586 & 4.09 \\
\hline
\end{tabular}

paste aeration speed, non-smooth aeration, and even the gas blockage, which is not good for the strength development of the product after autoclaving. Therefore, $60{ }^{\circ} \mathrm{C}$ was selected as the best static curing temperature.

\subsection{Analysis of hydration products}

\subsubsection{Phase analysis of AAC sample}

XRD was used to analyse the composition of the AAC samples. It qualitatively analysed various hydrated minerals formed mainly of calcium silicate, and their types; semi-quantitatively analyse the amount of production, which has a decisive influence on the performance of the AAC. Fig. 5 shows the XRD spectra of the AAC samples under the optimal mixture ratio of various factors.
It can be seen from Fig. 5 that the main phases in the AAC samole after autoclaving were $0.9 \mathrm{~nm}$ tobermorite $\left(\mathrm{Ca}_{5} \mathrm{Si}_{6} \mathrm{O}_{18} \mathrm{H}_{2}\right), 1.1 \mathrm{~nm}$ tobermorite $\left(\mathrm{Ca}_{5} \mathrm{Si}_{6} \mathrm{O}_{17} \cdot 5 \mathrm{H}_{2} \mathrm{O}\right)$ and $1.4 \mathrm{~nm}$ tobermorite $\left(\mathrm{Ca}_{5} \mathrm{Si}_{6} \mathrm{O}_{18} \mathrm{H}_{2} \cdot 8 \mathrm{H}_{2} \mathrm{O}\right)$, quartz, ferrotschermakite, hornblende, anhydrite, calcite, and dolomite. During the autoclaving process of the sample, as the $\mathrm{SiO}_{2}$ in the IOT and siliceous raw materials continuously dissolved, it reacted with calcareous materials such as lime to form the hydrated producttobermorite. A variety of water bound tobermorite was formed, which may be related to the composition of the AAC products (including water moisture) and the heterogeneity of particle size. Its formation indicates the coexistence of tobermorite with different bound water content in nature [18]. The ferrotschermakite $\mathrm{Ca}_{2} \mathrm{Fe}_{3} \mathrm{Al}_{2}\left(\mathrm{Si}_{6} \mathrm{Al}_{2}\right) \mathrm{O}_{22}(\mathrm{OH})_{2}$ in the product has a double-chain structure. Due to the addition of active $\mathrm{CaO}$ and $\mathrm{Al}$ powder in the sample, $\mathrm{Ca}^{2+}$ and $\mathrm{Al}^{3+}$ were ion-exchanged with $\mathrm{Fe}^{2+}$ and $\mathrm{Si}^{4+}$ in amphibole $\left(\mathrm{Fe}_{7} \mathrm{Si}_{8} \mathrm{O}_{22}(\mathrm{OH})_{2}\right)$ to form ferrotschermakite under high temperature steam curing conditions [19]. In the XRD pattern of the finished sample, anhydrite was generated, which was the residue after the reaction of FGDG in the system, while calcite was caused by the carbonization of the sample.

In the raw tailings such as the dolomite and hornblende, their characteristic peaks in the samples still existed after autoclaving, which must be due to its low activity under the autoclave conditions used in this system, making it impossible for all to participate in the reaction. The IOT minerals such as plagioclase, chlorite, and biotite were decomposed after autoclaving, entered the tobermorite structure, and form a new mineral phase, which is extremely beneficial to the development of sample strength. By comparing Fig. 1 with Fig. 5, it can be found that the intensity of quartz's diffraction peak was obviously decreased, which indicates that there was some residual after the quartz participat-

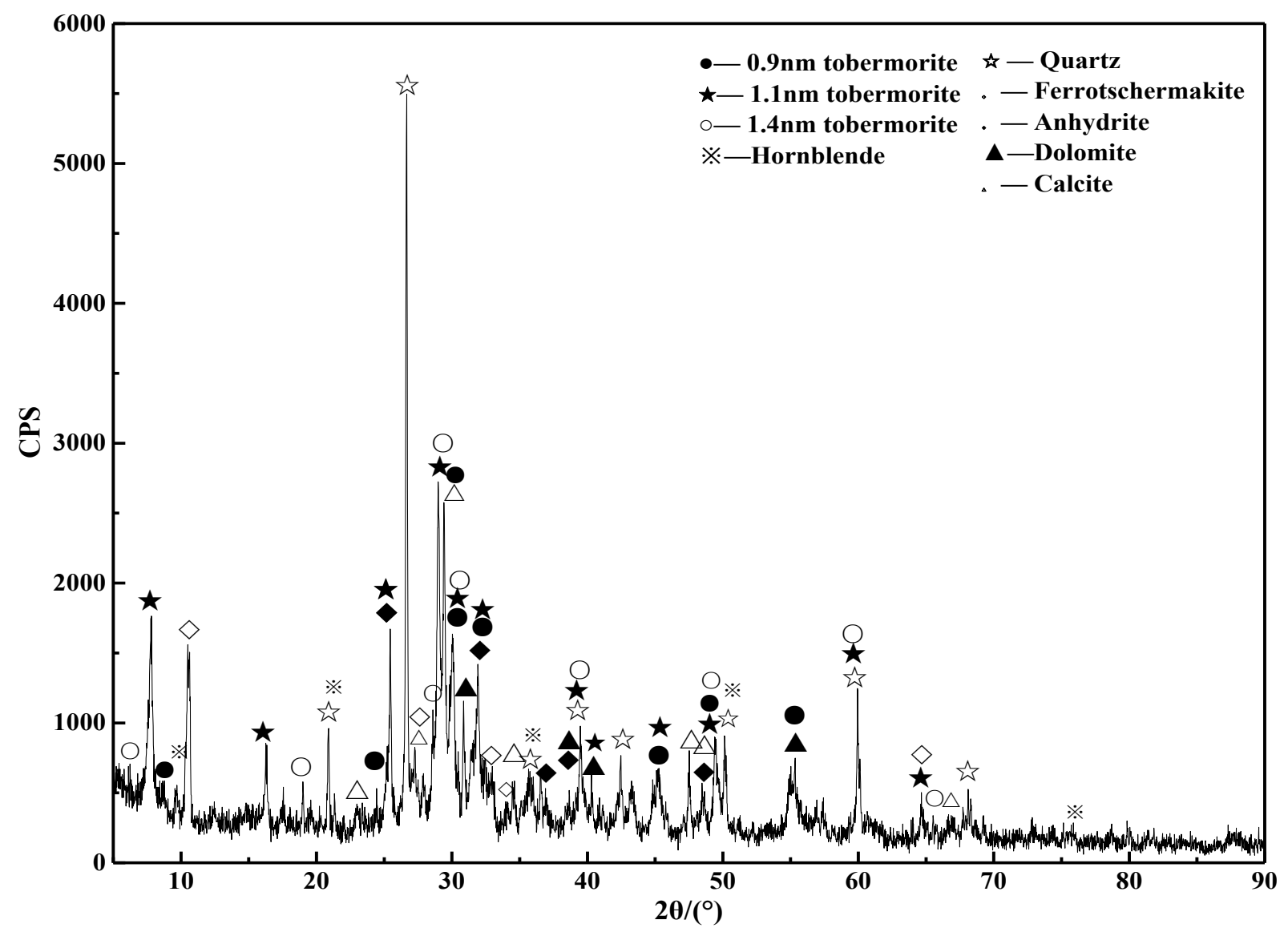

Figure 5. XRD spectra of A8 AAC samples 

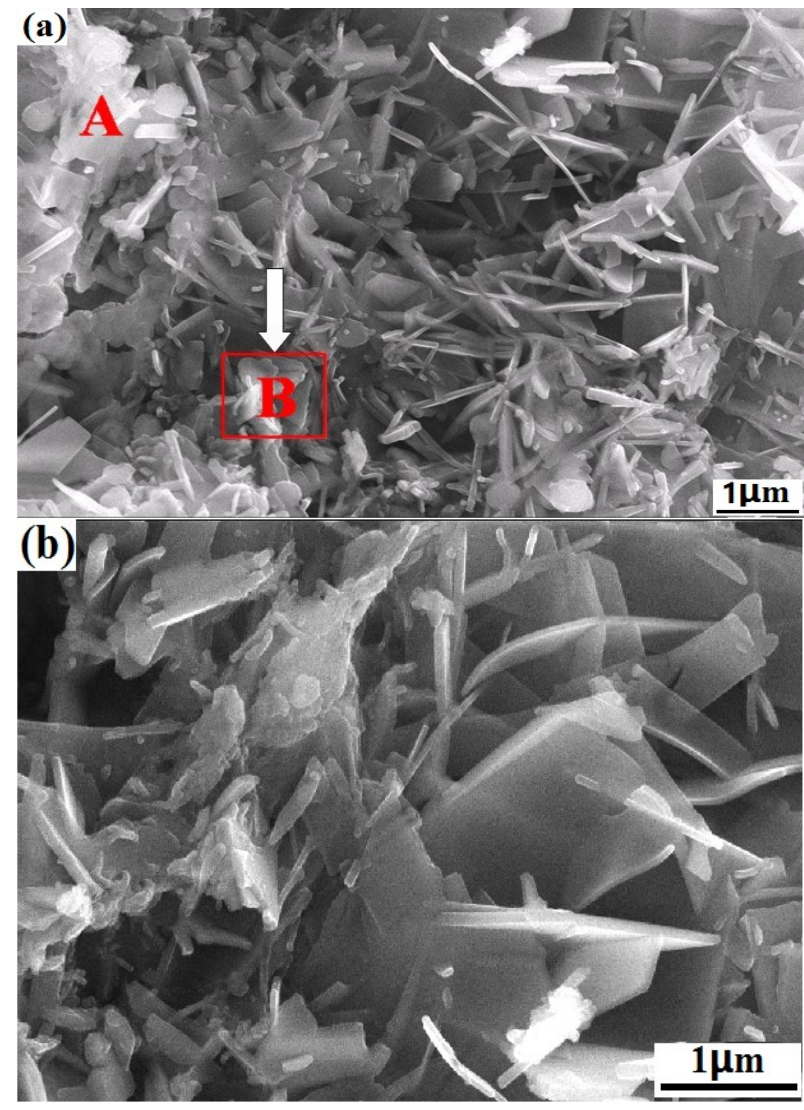

Figure 6. SEM micrographs of A8 AAC sample. (a) 30,000-fold enlargement of hydration products of samples, (b) 50,000-fold enlargement of hydration products of region B in Fig. 6 (a)

ing in the reaction, and the main residual aggregate of quartz existed. In addition, the XRD pattern had a certain dispersed background, which proves that certain amorphous (non-diffractive) substance existed in the sample A8, and there were some small particle sizes in the product, resulting in broadening of the diffraction peaks, and merging into the XRD diffraction background [20].

\subsubsection{Analysis for micro-morphology of hydration products}

Fig. 6 (a) shows the autoclaved AAC samples, in which the hydration products were densely clustered, and low crystallinity or amorphous C-S-H gels (A in the Fig. 6(a)) and a large amount of wellcrystallinity tobermorite in the shape of willow leaf or leaf (B in the Fig. 6(b)) were formed on the sample section; C-S-H gels acted as a "binder" to OPC these dense hydration products together and form a good network-like frame structure, which can change the pore structure of the product, and better resist external loads, and under stress, makes it not easy to cause stress concentration, playing a role in improving the strength of the samples [21-26]. In Fig. 6 (b), it can be seen from the enlarged image of B from Fig. 6 (a) that the hydrated product tobermorite had a good crystal form, and at the same time, and there were unreacted quartz particles around the plate- or flake-shaped material; due to the different choices of the field of view, the number of quartz particles also varied.

\subsection{Strength formation mechanism analysis of the AAC samples}

The same as that of other types of AAC, the reaction process of the AAC doped with the IOT, SS, OPC, lime include the static curing stage and the autoclaving curing stage under high temperature and pressure.

During the static curing period, hydration of the OPC occurred in the casting slurry and the body, quicklime decomposed, and low crystallinity or amorphous C-S-H gels, $\mathrm{Ca}(\mathrm{OH})_{2}$, and a small amount of calcium sulfoaluminate hydrate were formed. Under the conditions of hot alkali excitation, a small amount of $\mathrm{SiO}_{2}$ components in IOT and $\mathrm{SS}$ began to show chemical activity, and reacted with $\mathrm{Ca}(\mathrm{OH})_{2}$ produced by quicklime digestion to form $\mathrm{C}-\mathrm{S}-\mathrm{H}$ gels, so that the product body obtains early strength and is convenient for handling and cutting.

During the autoclave curing stage, as the temperature increased, more $\mathrm{SiO}_{2}$ in the IOT and SS accelerated to dissolve, and reacted with $\mathrm{Ca}(\mathrm{OH})_{2}$ to form C-S-H gels, while the dual-alkali silicate in the cement reacted with $\mathrm{SiO}_{2}$ to form the tobermorite and C-S-H gels. Under high-temperature and high-pressure steaming environment, active ionization interacted with $\mathrm{OH}^{-}$, and the Si-O and $\mathrm{Al}-\mathrm{O}$ bonds in the system are broken, which promoted the $\mathrm{SiO}_{2}$ and $\mathrm{Al}_{2} \mathrm{O}_{3}$ components in the raw material system to show activity, and combines with $\mathrm{Ca}(\mathrm{OH})_{2}$ to produce the hydration product and form a supersaturated solution. By maintaining enough steaming time, the hydration products were formed, and interweaved into network after crystallization and nucleation, showing gel property. Since some minerals in the IOT and SS participated in the formation reaction of hydration product under hightemperature autoclaving conditions, more C-S-H gels and tobermorite were formed. These hydration products were tightly wrapped on the surface of the coarse iron tailings particles, giving the product strength. Based on the mechanism analysis of the above, it can be found that the strength of the AAC depends on the cementation of the hydration products such as $\mathrm{C}-\mathrm{S}-\mathrm{H}$ gels and tobermorite (formed by the reaction of cement, lime and the active components $\mathrm{SiO}_{2}$ and $\mathrm{Al}_{2} \mathrm{O}_{3}$ in the raw materials system) with other ingredients together.

\section{CONCLUSIONS}

(1) Using low-silicon high-iron-type IOT as the main siliceous materials, qualified products of the AAC in A3.5, B06-class regulated by national standards can be prepared. The optimized ratio is: the specific surface area of iron tailings $311 \mathrm{~m}^{2} \cdot \mathrm{kg}^{-1}$, the mass ratio of IOT, SS, lime, OPC, FGDG 40:20:25:10:5, the water-to-material ratio 0.58, the amount of aluminium powder added to be $0.06 \%$ of the total dry material, and the curing temperature of $60^{\circ} \mathrm{C}$.

(2) XRD and SEM analysis showed that under high-temperature autoclaved conditions, the hydration products of the AAC were a large number of well-crystallized tobermorite in the shaper of willow leaf or leaf with different combined water contents and low-crystallized or amorphous $\mathrm{CSH}$ gel; $\mathrm{Ca}^{2+}$ and $\mathrm{Al}^{3+}$ were ion-exchanged with $\mathrm{Fe}^{2+}$ and $\mathrm{Si}^{4+}$ in amphibole $\left(\mathrm{Fe}_{7} \mathrm{Si}_{8} \mathrm{O}_{22}(\mathrm{OH})_{2}\right)$, respectively, to form ferrotschermakite; plagioclase, biotite and chlorite were completely decomposed after participating in the reaction of the system; anhydrite was generated, as the residue of the reacted FGDW in the system, while the calcite was caused by carbonization of the product; dolomite and ordinary amphibole in iron tailings with low activity did not participate in the system reaction; the quartz participated in the system reaction, but leaving some residual particles behind.

(3) The mechanism analysis showed that under high temperature autoclaving conditions, the IOT could show good activity, and the active components $\mathrm{SiO}_{2}$ and $\mathrm{Al}_{2} \mathrm{O}_{3}$ in the raw material system have an enhanced ability to participate in chemical reactions; the active components $\mathrm{SiO}_{2}$ and $\mathrm{Al}_{2} \mathrm{O}_{3}$ reacted with the cement and lime to form hydration products such as $\mathrm{C}-\mathrm{S}-\mathrm{H}$ gels and tobermorite, which can help to enhance the product strength by cementing together with other components. 


\section{ACKNOWLEDGMENTS}

The authors gratefully acknowledge financial support from China Postdoctoral Science Foundation (2016M602082), supported by Natural Science Foundation of Hebei Province (E2018402119), supported by Natural Science Foundation of Shaanxi Province (2019JLM-49), supported by Shaanxi Science and Technology Benefit People Project (2018ZY-HM-01), supported by Science and Technology Research Project of Higher Education Universities in Hebei Province (ZD2016014, QN2016115), supported by Comprehensive Utilization of Tailing Resources Key Laboratory of Shaanxi Province (2017SKYWK008), supported by Jiangxi Postdoctoral Daily Fund Project (2016RC30), supported by Jiangxi Postdoctoral Research Project (2017KY19), supported by State Key Laboratory of Solid Waste Reuse for Building Materials (SWR-2019-008).

\section{REFERENCE}

[1] Wang X L, Ren R C, Liu Y. Application of DTA in preparation of glass-ceramic made by iron tailings, Procedia Earth and Planetary Science, 2009, 1(1),750-753.

[2] Zhang S, Xue X, Liu X. Current situation and comprehensive utilization of iron ore tailing resources. Journal of Mining Science, 2006, 42(4), 403-408.

[3] Li J, Wang Q, Liu J H, Li P. Synthesis process of forsterite refractory by iron ore tailings. Journal of Environmental Sciences, 2009, 21 (suppl.1), 92-95.

[4] Li C, Sun H H, Bai J, Li L T. Innovative methodology for comprehensive utilization of iron ore tailings: Part 1 . The recovery of iron from iron ore tailings using magnetic separation after magnetizing roasting. Journal of Hazardous Materials, 2010, 174(1-3), 71-77.

[5] Li C, Sun H H, Yi Z L, Li L T. Innovative methodology for comprehensive utilization of iron ore tailings: Part 2: The residues after iron recovery from iron ore tailings to prepare cementitious material, Journal of Hazardous Materials, 2010, 174(1-3), 78-83

[6] Chen Y L, Zhang Y M, Chen T J, Zhao Y L, Bao S U. Preparation of eco-friendly construction bricks from hematite tailings. Construction and Building Materials, 2011, 25(4), 2107-2111.

[7] Liu Y S, Du F, Yuan L, Zeng H, Kong S F. Production of lightweight ceramisite from iron ore tailings and its performance investigation in a biological aerated filter (BAF) reactor. Journal of Hazardous Materials, 178(1-3), 999-1006.

[8] Zhao Y L, Zhang Y M, Chen T J, Chen Y L, Bao S U. Preparation of high strength autoclaved bricks from hematite tailings, Construction and Building Materials, 2012, 28(1), 450-455.

[9] Yi Z L, Sun H H, Wei X Q, Li C. Iron ore tailings used for the preparation of cementitious material by compound thermal activation, International Journal of Minerals, Metallury and Materials, 16(3), 355(2009)

[10]Yi Z L, Sun H H, Li C, Sun Y M, Li Y. Relationship between polymerization degree and cementitious activity of iron ore tailings[J]. International Journal of Minerals, Metallury and Materials, 2010, 17(1), 116-120.

[11]Liu S J, Hu Q Q, Zhao F Q, Chu X M. Utilization of steel slag, iron tailings and fly ash as aggregates to prepare a polymer-modified waterproof mortar with a core-shell styrene-acrylic copolymer as the modifier. Construction and Building Materials, 2014, 72, 15-22.

[12]Lu H J, Qi C C, Chen Q S, Gan D Q, Xue Z L, Hu Y J. A new procedure for recycling waste tailings as cemented paste backfill to underground stopes and open pits. Journal of Cleaner Production, 2018, 188, 601-612.

[13]Coussy S, Benzaazoua M, Blanc D, Moszkowicz P, Bussière B.
Arsenic stability in arsenopyrite-rich cemented paste backfills: A leaching test-based assessment. Journal of Hazardous Materials, 2011, 185(2-3): 1467-1476.

[14]Li D Z, Ni W, Zhang J W, Wu H, Zhang Y Y. Phase transformation of iron Ore tailings during autoclaved curing. Journal of the Chinese Ceramic Society, 2011, 39(4): 708-713.

[15]Roman A. Buyanova, Victor V. Molchanov, Vladimir V. Boldyrev. Mechanochemical activation as a tool of increasing catalytic activity, Catalysis Today, 2009, 144(3-4), 212-218.

[16]Sydorchuk V, Khalameida S, Zazhigalov V, Skubiszewska-Zięba J, Leboda R, Wieczorek-Ciurowac K. Influence of mechanochemical activation in various media on structure of porous and nonporous silicas, Applied Surface Science, 2010, 257(2), 446-450.

[17]Senneca O, Salatino P, Chirone R, Cortese L, Solimene R. Mechanochemical activation of high-carbon fly ash for enhanced carbon reburning, Proceedings of the Combustion Institute, 2011, 33(2), 2743-2753.

[18]Maeshima T, Nomab H, Sakiyama M, Mitsuda T. Natural 1.1 and $1.4 \mathrm{~nm}$ tobermorites from Fuka, Okayama, Japan: Chemical analysis, cell dimensions, ${ }^{29} \mathrm{Si}$ NMR and thermal behavior, Cement and Concrete Research, 2003, 33(10), 1515-1523.

[19]Gittos M F, G. W. Lorimer G F, Champness P E. An electronmicroscopic study of precipitation (exsolution) in an amphibole (the hornblende-grunerite system), Journal of Materials Science, 1974, 9(2), 184-192.

[20]Bensted J, Barnes P. Structure and performance of cements, 2nd edition[M]. New York: Spon Press, 2002.

[21]Bonaccorsi E, Merlino S., Kampf A R. The crystal structure of tobermorite $14 \AA$ (Plombierite), a C-S-H phase, Journal of the American Ceramic Society, 2005, 88(3), 505-512.

[22]Wang C L, Ni W, Zhang S Q, Wang S, Gai G S, Wang W K. Preparation and properties of autoclaved aerated concrete using coal gangue and iron ore tailings $[\mathrm{J}]$. Construction and Building Materials, 2016, 104: 109-115.

[23]Oh J E, Clark S M, Wenk H R, Monteiro P J M. Experimental determination of bulk modulus of $14 \AA$ tobermorite using high pressure synchrotron X-ray diffraction, Cement and Concrete Research, 2012, 42(2), 397-403.

[24]Huang X Y, Ni W, Cui W H, Wang Z J, Zhu L P. Preparation of autoclaved aerated concrete using copper tailings and blast furnace slag. Construction and Building Materials, 2012, 27(1): 1-5.

[25]Cui X W, Wang C L, Ni W, Di Y Q, Cui H L, Chen L. Study on the reaction mechanism of autoclaved aerated concrete based on iron ore tailings [J]. Romanian Journal of Materials, 2017, 47 (1): $46-53$.

[26]Liang X Y, Yuan D X, Li J, Wang C L, Lin X R, Chang N. Preparation and phase characteristics of autoclaved aerated concrete using iron ore tailings [J]. Romanian Journal of Materials, 2018, 48 (3):381 -387 